\title{
AVALIAÇÃO MICROBIOLÓGICA DE CASOS DE MASTITE SUBCLÍNICA EM REBANHO LEITEIRO JERSEY DE UM HOSPITAL VETERINÁRIO UNIVERSITÁRIO LOCALIZADO NO INTERIOR DO ESTADO DE SÃO PAULO
}

\author{
EVALUATION OF CLINICAL AND SUBCLINICAL MASTITIS CASES IN A JERSEY \\ DAIRY CATTLE FROM A UNIVERSITARY VETERINARY HOSPITAL SITED IN \\ MIDDLE SAO PAULO STATE, BRAZIL
}

Y. G. MARANGONI'*, F. Z. ARAÚJO', M. F. A. FILHO ${ }^{1}$, M. Z. TRONCARELLI ${ }^{2}$

\begin{abstract}
RESUMO
A mastite é uma das afecções mais importantes em bovinocultura leiteira, por ocasionar consideráveis perdas de produção, descarte precoce de animais, contaminação microbiana do leite, custos com tratamentos, menor rendimento industrial, entre outros fatores. O monitoramento periódico do rebanho, por meio da realização de provas para detecção de casos de mastite clínica e subclínica, é de fundamental importância para a profilaxia e controle da doença, evitando a ocorrência de perdas econômicas, bem como riscos à saúde pública. Na Faculdade de Medicina Veterinária campus FAEF Garça-SP, são manejados bovinos leiteiros da raça Jersey, composto por 30 vacas em lactação, com produção média de 30 litros de leite/animal/dia. Para avaliação do status de mastite no rebanho, realizaram-se as provas de CMT, isolamento microbiológico e antibiograma das cepas isoladas. A prevalência de mastites subclínicas no rebanho foi de $29,6 \%$. Trinta e cinco amostras de leite obtidas dos tetos positivos ao CMT foram semeadas em ágar sangue bovino a 5\% e MacConkey, e incubadas por 72 horas a $37^{\circ} \mathrm{C}$, com leituras a cada 24 horas. Para o antibiograma foram utilizados discos de tetraciclina, cefalexina, ciprofoxacina, ceftriaxona, penicilina, norfloxacina, neomicina, enrofloxacina e gentamicina. Das 35 amostras avaliadas, $22(62,85 \%)$ foram positivas ao isolamento microbiológico. Staphylococcus aureus foram isolados em 12 amostras $(54,5 \%)$ e estafilococos coagulase negativos $(\mathrm{SCN})$ foram isolados a partir de 10 amostras (45,5\%). Estes constituem patógenos contagiosos de mastite, e apresentaram importante resistência in vitro à gentamicina e à neomicina. Com base nestes resultados, novas medidas de manejo estão sendo adotadas, de forma a reduzir o número de casos de mastite clínica e subclínica no rebanho, e os resultados serão apresentados a posteriori. Conclui-se que, para o adequado controle de mastite em rebanhos leiteiros, especialmente de casos subclínicos, é imprescindível a adoção de monitoramento periódico dos animais, associada a medidas higiênico-sanitárias.
\end{abstract}

PALAVRAS-CHAVE: VACA. MASTITE. PREVALÊNCIA. MICRO-ORGANISMOS. PROFILAXIA.

AGRADECIMENTO: FAEF - Garça-SP.

ÁREA TEMÁTICA: Doenças Infecciosas. 